Check for updates

Cite this: RSC Adv., 2017, 7, 21298

Received 11th February 2017

Accepted 18th March 2017

DOI: 10.1039/c7ra01735a

rsc.li/rsc-advances

\section{Peptide-binding induced inhibition of chemokine CXCL12†}

\author{
Hongyang Duan, (DD abd Ling Zhu, ${ }^{\text {ad }}$ Jiaxi Peng, ${ }^{\text {ad }}$ Mo Yang, ${ }^{\text {ad }}$ Hanyi Xie, ${ }^{\text {abd }}$ \\ Yuchen Lin, ${ }^{\text {ad }}$ Wenzhe Li, ${ }^{\text {abd }}$ Changliang Liu, ${ }^{\text {ad }}$ Xiaojin Li, ${ }^{c}$ Hua Guo, ${ }^{c}$ Jie Meng, ${ }^{c}$ \\ Haiyan $\mathrm{Xu}^{* c}{ }^{* c}$ Chen Wang ${ }^{\star a d}$ and Yanlian Yang ${ }^{\star a d}$
}

The chemokine CXCL12, and its receptor CXCR4, have been recognized to be involved in various instances of cancer metastasis. The CXCL12/CXCR4 axis has emerged as a potential target for cancer therapy. Here, we demonstrate a designed peptide (W4) targeting CXCL12 with high binding affinity, and describe its significant inhibitory effect on the CXCL12/CXCR4 axis. We show that W4 has comparable binding affinity $\left(K_{D}=5.7 \times 10^{-8} \mathrm{M}\right)$ to that of the antibody of CXCL12 $\left(K_{\mathrm{D}}=3.0 \times 10^{-9} \mathrm{M}\right)$ using the surface plasma resonance (SPR) technique. Upon introduction of W4, the circular dichroism (CD) spectra show that the $\alpha$-helical structure of CXCL12 gradually transformed into a $\beta$-sheet and random coil. These effects lead to the significant inhibitory effects on the CXCL12/CXCR4 axis using the CXCR4-positive breast cancer cell lines MCF-7 and MDA-MB-231 and the leukemia cell lines HL-60 and U937 as models. The results show that W4 significantly inhibits CXCL12-induced cell migration of MCF-7, MDA-MB-231, HL-60 and U937 even to $20.0 \%$ when the mole ratio is $1: 1$, completely abolishing the effect of CXCL12. These effects may provide evidence of the modulating ligand-receptor interactions of peptides as antiligand molecules that differ from the traditional receptor antagonists leading to therapeutic agents.

\section{Introduction}

Cancer metastasis is a major cause of morbidity and mortality. ${ }^{1}$ In the process of metastasis, cancer cells locally invade the surrounding tissue, enter the lymph and blood circulation, survive in the circulation, exit at distant organs, and adapt to the new microenvironments there. ${ }^{2}$ CXCL12, also known as stromal derived factor-1 (SDF-1), belongs to the family of CXC chemokines that bind to and activate the seven-transmembrane G protein-coupled receptor CXCR4. ${ }^{3}$ The CXCL12/CXCR4 axis is reported to be involved in various cellular behaviors such as cell migration, adhesion and invasion. ${ }^{4}$ Under normal conditions, the CXCL12/CXCR4 axis helps leukocyte recruitment and is critical for homing and retention of hematopoietic cells to the bone marrow. In addition to its physiological roles, CXCR4 has

${ }^{a}$ CAS Key Laboratory of Standardization and Measurement for Nanotechnology, CAS Key Laboratory of Biological Effects of Nanomaterials and Nanosafety, CAS Center for Excellence in Nanoscience, National Center for Nanoscience and Technology, Beijing 100190, P. R. China. E-mail:wangch@nanoctr.cn; yangyl@nanoctr.cn; Tel: +86-10-82545561; +86-10-82545559

${ }^{b}$ Academy for Advanced Interdisciplinary Studies, Peking University, Beijing 100871, P. R. China

'Institute of Basic Medical Sciences, Chinese Academy of Medical Sciences \& Peking Union Medical College, Beijing 100005, P. R. China. E-mail: xuhy@pumc.edu.cn; Tel: +86-10-69156437

${ }^{d}$ University of Chinese Academy of Sciences, Beijing 100049, P. R. China

$\dagger$ Electronic supplementary information (ESI) available. See DOI: 10.1039/c7ra01735a also been found to be a prognostic marker which is shown to regulate site-specific distant metastasis in various types of human tumors including breast, ${ }^{5,6}$ prostate $^{7,8}$ and colon tumors $^{9,10}$ and multiple myeloma. ${ }^{11}$ The high expression level of CXCR4 in tumor cells enables them to migrate to target tissues (like lung, liver and bone) that have an abundant source of the ligand CXCL12, which allows tumor cells to form directional migration via the CXCL12 chemotactic gradient. The influx of leukocytes into tissues has similarities with the invasion of tissues by metastasizing tumor cells, as well as hematopoietic tumors. For example, myeloid ${ }^{\mathbf{1 2 , 1 3}}$ and lymphoid ${ }^{14,15}$ leukemia cells also have a high level of CXCR4 expression, which induces leukemia migration towards stromal cells secreting CXCL12, and as a result of this they reside in the microenvironment that protects them from chemotherapy-induced cell death. ${ }^{16,17}$

As noted, increasing efforts have been made in impeding the function of the CXCL12/CXCR4 axis by targeting either the ligand or the receptor using small molecules, ${ }^{18}$ peptides ${ }^{19,20}$ and antibodies. ${ }^{21,22}$ Most of these antagonists are still at the stage of preclinical study. ${ }^{23}$ Previous studies mostly focused on the blockade of CXCR4 with CXCR4 antagonists, however, targeting the other part of this axis, the chemokine CXCL12, represents an attractive alternative approach. It has been reported that saccharides hinder the migration of human tumor cells via blocking of the interaction between CXCL12 and CXCR4, and these findings were supported by the structural analysis of CXCL12's interactions with saccharides. ${ }^{\mathbf{2 4 , 2 5}}$ Furthermore, the 
treatment of human $\mathrm{CD} 4^{+} \mathrm{T}$ lymphocytes with a series of chalcones inhibited CXCL12-induced migration. ${ }^{26}$ By analogy to the effect of neutralizing antibodies, these molecules behave as neutralizing compounds that may prove to have valuable pharmacological and therapeutic potentials. However, peptides are rarely reported binding to the chemokine itself to neutralize its biological activity. Considering that peptides are readily synthesized, metabolically cleaved and rapidly cleared from the body without introducing serious immune responses and toxic side effects, it is very necessary and of great significance to develop peptides that target CXCL12 to provide more therapeutic options in the treatment of tumor metastasis.

Allosteric modulation of protein-substrate interactions results from binding of an allosteric ligand to a distinct site on the protein, in a way that does not directly compete with the binding site of its cognate substrate. ${ }^{27}$ Binding of the allosteric ligand may increase or decrease the affinity to the cognate substrate through minor modifications to the conformation of the protein, thus opening or closing the active site and resulting in positive or negative protein activity. ${ }^{28} \mathrm{Here}$, we have identified a CXCL12 recognition peptide W4 with high binding affinity to target and modulate the secondary structure of CXCL12, and we described its significant inhibitory effect on the CXCL12/CXCR4 axis using the CXCR4-positive breast cancer cell lines MCF-7 and MDA-MB-231, and leukemia cell lines HL-60 and U937. We speculate a potential allosteric coupling at the binding site of CXCL12 to W4 and the conformational change caused might transmit the signal to the active site of CXCL12, which dramatically reduces the interaction of CXCL12 with its receptor CXCR4. These effects may provide a feasible strategy for modulating the ligand-receptor interactions of peptides leading to therapeutic anti-ligand agents.

\section{Experimental section}

\subsection{Peptide W4}

The peptide W4 with the sequence of GGRGDLDWIQRYLRDA was selected from screening of a collection of de novo designed peptides based on the amyloid proteins and fragments of various proteins. A surface plasmon resonance (SPR)-based selection process was performed for screening peptide ligands with high binding affinity. This collection of peptides was examined using scanning probe microscopy (SPM) in our previous studies for unraveling various interactions, such as the hydrogen bonding, electrostatic and hydrophobic interactions between the side chains, and peptide assemblies. ${ }^{29-31}$ The peptide W4 used in this study (purity 98\%), with and without fluorescein isothiocyanate (FITC) labeling, was purchased from GL Biochem Ltd, Shanghai, China and used without further purification.

\subsection{Cell culture}

The human promyelocytic leukemia HL-60 cells and myelomonocytic leukemia U937 cells were purchased from the Chinese Academy of Medical Science \& Peking Union Medical College, Beijing, China. The human breast cancer MCF-7 cells and MDA-MB-231 cells were kindly provided as a gift from Professor Chunying Chen at the National Center for Nanoscience and Technology, Beijing, China. The MCF-7, HL-60 and U937 cells were cultured in RPMI-1640 culture medium (Gibco, USA) and the MDA-MB-231 cells in DMEM culture medium (Gibco, USA). The culture media were supplemented with $10 \%$ heat-inactivated fetal bovine serum (FBS; Gibco, USA) and 1\% streptomycin-penicillin. The cells were placed in a dish in the cell culture incubator with $5 \% \mathrm{CO}_{2}$ at $37{ }^{\circ} \mathrm{C}$.

\subsection{Surface plasmon resonance (SPR)}

The binding affinity and binding dynamics parameter of W4 and anti-CXCL12 with CXCL12 were investigated using an SPR system (Kx5, Plexera, USA) at $25^{\circ} \mathrm{C}$. CXCL12 was in the flowing phase, and the peptide and antibody were immobilized on the commercial SPR chips with modification of the self-assembled layer of the carboxyl group-containing thiol molecules via a covalent bond on the gold (50 nm) coated glass (Plexera, USA). CXCL12 (R\&D Systems, USA) was dissolved in phosphate buffer saline (PBS; Hyclone, USA) at a series of concentrations (50, 100 and $200 \mathrm{nM}$ ), and $1 \mathrm{mg} \mathrm{mL}^{-1} \mathrm{~W} 4$ and anti-CXCL12 (RayBiotech, USA) dissolved in triple distilled water were dropped on the chip. Then the surface was washed with water twice. The realtime binding signals were recorded and analyzed by a Data Analysis Module (DAM, Plexera, USA). The binding analysis was performed using BIAevaluation 4.1 software (Biocore, GE Healthcare, USA).

\subsection{ELISA assay}

$0.1 \mu \mathrm{g}$ of CXCL12 diluted in $50 \mu \mathrm{L}$ of coating buffer $(0.1 \mathrm{M}$ sodium bicarbonate, $\mathrm{pH}$ 9.6) was added to each well of a 96-well microplate. Then the plate was incubated for 2 hours at $37^{\circ} \mathrm{C}$, washed three times with PBS containing $0.01 \%$ Tween 20 (PBST) and blocked for $2 \mathrm{~h}$ at $37{ }^{\circ} \mathrm{C}$ with $5 \%$ skim milk in PBST. The plate was then washed three times with PBST and $50 \mu \mathrm{L}$ of antiCXCL12 diluted in 5\% skim milk in PBST with different concentrations of $\mathrm{W} 4$ was added and incubated for $1 \mathrm{~h}$ at $37^{\circ} \mathrm{C}$. The plate was washed three times with PBST and $100 \mu \mathrm{L}$ of horseradish peroxidase (HRP)-conjugated anti-IgG (Cell signaling Technology, USA) diluted in 5\% skim milk in PBST was added and incubated for $1 \mathrm{~h}$ at $37^{\circ} \mathrm{C}$. The plate was washed three times with PBST and developed using 3,3,5,5-tetramethylbenzidine (TMB). The reaction was stopped with $100 \mu \mathrm{L}$ of $2 \mathrm{M} \mathrm{H}_{2} \mathrm{SO}_{4}$ and the absorbance of each well read using a microplate reader (Infinite M200, Tecan, Switzerland) at a test wavelength of $450 \mathrm{~nm}$.

\subsection{Dot blot assay}

$0.1 \mu \mathrm{g}$ of CXCL12 diluted in $5 \mu \mathrm{L}$ of PBS was spotted onto a nitrocellulose membrane $(0.45 \mu \mathrm{m}$, Pierce, USA $)$ and dried at room temperature. Then the membrane was blocked with $5 \%$ skim milk in Tris-buffered saline (TBS) containing $0.01 \%$ Tween 20 (TBST) for $1 \mathrm{~h}$ at room temperature, washed three times with TBST and incubated with anti-CXCL12 diluted in 5\% skim milk in TBST with different concentrations of W4 overnight at $4{ }^{\circ} \mathrm{C}$. The membrane was washed with TBST three times and 
incubated for $1 \mathrm{~h}$ with HRP-conjugated anti-IgG in 5\% skim milk in TBST at room temperature. Following five washes with TBST, the membrane was developed with an ECL chemiluminescence system.

\subsection{Circular dichroism (CD) spectroscopy assay}

The CD experiments were performed using a quartz cell with $0.1 \mathrm{~cm}$ path length using a spectropolarimeter (J-1500, JASCO, Japan) equipped with a microcomputer. The CXCL12 solution at $5 \mu \mathrm{M}$ was prepared in triple distilled water with different concentrations of W4. The CD spectra of CXCL12 were recorded between $190 \mathrm{~nm}$ and $260 \mathrm{~nm}$ with a scan speed of $200 \mathrm{~nm}$ $\min ^{-1}$, spectral bandwidth of $2 \mathrm{~nm}$, and data pitch of $0.5 \mathrm{~nm}$. Every CD spectrum data of CXCL12 used was the average of three scans with the background of the peptide and the solvent subtracted.

\subsection{Molecular docking}

The NMR structure of the chemokine CXCL12 was retrieved from the RSCB Protein Data Bank (PDB ID: 2SDF). The structure of W4 was obtained by PyMol, and the formation converted and 3D structure generated by Open Babel. The rotatable bonds within the peptide were defined using AutoDockTools. AutoDock Vina was used for the automated docking simulation. The standard parameters were created with Raccoon, a script program in the AutoDock software package, and used. Calculations were performed with a 26-node PC cluster in which each node has a 16-core central processing unit (2.8 GHz, Pentium-D, Intel, USA). The lowest binding free energy was recorded as the binding affinity between W4 and CXCL12.

\subsection{Wound healing assay}

The MCF-7 and MDA-MB-231 cells were plated in a 6-well plate at a concentration of $50 \times 10^{4}$ and $30 \times 10^{4}$ cells per well, respectively, and allowed to form a confluent monolayer overnight. Then the monolayer was scratched with a $10 \mu \mathrm{L}$ pipette tip, washed 3 times with PBS to remove the floating cells, and treated with different concentrations of $\mathrm{W} 4$ in culture medium in the presence or absence of $100 \mathrm{ng} \mathrm{mL}^{-1}$ CXCL12. The cells were photographed (IX71, OLYMPUS, Japan) at 3 randomly selected sites per well and incubated for $24 \mathrm{~h}$ at $37^{\circ} \mathrm{C}$. The cells were then photographed again at the selected sites. The actual migration of the cells was analyzed according to the original and final wound zone.

\subsection{Transwell assay}

The transwell assay was applied using millicell hanging cell culture inserts ( $5 \mu \mathrm{m}$ for U937, $8 \mu \mathrm{m}$ for MCF-7, MDA-MB-231 and HL-60; Millipore, Switzerland). The MCF-7 $\left(10 \times 10^{4}\right.$ cells per chamber), MDA-MB-231 (10 $\times 10^{4}$ cells per chamber), HL-60 $\left(20 \times 10^{4}\right.$ cells per chamber $)$ and U937 $\left(20 \times 10^{4}\right.$ cells per chamber) cells were plated into the upper chambers of the inserts in culture medium. Then the inserts were placed into a well of a 24 -well plate containing $800 \mu \mathrm{L}$ culture medium in the presence or absence of CXCL12 treated with different concentrations of W4. The concentrations of CXCL12 were 100 $\mathrm{ng} \mathrm{mL} \mathrm{m}^{-1}$ for the MCF-7 and MDA-MB-231 cells, $200 \mathrm{ng} \mathrm{mL}^{-1}$ for the HL-60 cell and $50 \mathrm{ng} \mathrm{mL}^{-1}$ for the U937 cell (at these concentrations, the cells reached the maximum of migration, data not shown). After a $24 \mathrm{~h}$ incubation at $37{ }^{\circ} \mathrm{C}$, for the MCF-7 and MDA-MB-231 cells, the top surface of the insert was scraped using a cotton swab, and the cells on the lower surface of the membrane were fixed and stained with crystal violet. The cells that had migrated to the bottom of the membrane were visualized and counted using a microscope (DMI3000B, Leica, Germany). For each replicate, the cells in five randomly selected fields were counted and averaged. For the HL-60 cells and U937 cells, the cells migrating to the lower chambers were counted.

To confirm the absence of off-target effects of $\mathrm{W} 4$ on cell migration, the HL-60 and U937 cells were plated into the upper chambers of the inserts and then the inserts were placed in a well containing $800 \mu \mathrm{L}$ of culture medium in the presence of CXCL12 and $10 \mu \mathrm{g} \mathrm{mL}^{-1}$ anti-CXCL12 prior to the addition of W4. After $24 \mathrm{~h}$ incubation at $37{ }^{\circ} \mathrm{C}$, the cells migrating to the lower chambers were counted.

\subsection{Realtime fluorescence quantitative PCR}

The MCF-7, MDA-MB-231, HL-60 and U937 cells were maintained overnight in medium containing $0.5 \%$ FBS at $1 \times 10^{6}$ cells per well in a 6-well plate. After that, CXCL12 $\left(100 \mathrm{ng} \mathrm{mL} \mathrm{m}^{-1}\right.$ for MCF-7 and MDA-MB-231, $200 \mathrm{ng} \mathrm{mL}{ }^{-1}$ for HL-60 and $50 \mathrm{ng}$ $\mathrm{mL}^{-1}$ for U937) with and without $\mathrm{W} 4$ at the mole ratio of $1: 1$ was added into the medium for $15 \mathrm{~min}$ at $37^{\circ} \mathrm{C}$. The total RNA was extracted using Trizol (Life Technologies, USA), and then reverse transcribed with a QuantScript RT Kit (TIANGEN, China) for $1 \mathrm{~h}$ at $37{ }^{\circ} \mathrm{C}$, according to the instructions of the manufacturer. The following primers (Sangon Biotech, China) were used for the subsequent PCR: Vimentin (forward: $5^{\prime}$ GAA CGC CAG ATG CGT GAA ATG 3'; reverse: $5^{\prime}$ CCA GAG GGA GTG AAT CCA GAT TA $3^{\prime}$ ), N-cadherin (forward: $5^{\prime}$ GAG GAG TCA GTG AAG GAG TCA $3^{\prime}$; reverse: $5^{\prime}$ GGC AAG TTG GAG GGA TG $3^{\prime}$ ), MMP2 (forward: $5^{\prime}$ ACC CTC AGA GCC ACC CCT AA $3^{\prime}$; reverse: $5^{\prime}$ AGC CAG CAG TGA AAA GCC AG $3^{\prime}$ ), and MMP9 (forward: $5^{\prime}$ TCC CTG GAG ACC TGA GAA CC $3^{\prime}$; reverse: $5^{\prime}$ CGG CAA GTC TTC CGA GTA GTT $3^{\prime}$ ). The reverse transcription was checked with primers for the GAPDH gene (forward: $5^{\prime}$ GAG AAG GCT GGG GCT CAT TT $3^{\prime}$; reverse: $5^{\prime}$ AGT GAT GGC ATG GAC TGT GG $3^{\prime}$ ) as a control. Then the cDNA was subjected to PCR with a Realplex 4 (Eppendorf, Germany) and the cycling conditions were: $5 \mathrm{~min}$ at $95^{\circ} \mathrm{C}, 40$ cycles of $15 \mathrm{~s}$ at $95^{\circ} \mathrm{C}, 15 \mathrm{~s}$ at $60^{\circ} \mathrm{C}, 200 \mathrm{~s}$ at $72{ }^{\circ} \mathrm{C}$, and finally an elongation step of $5 \mathrm{~min}$ at $72{ }^{\circ} \mathrm{C}$.

\subsection{Western blot analysis}

The MCF-7, MDA-MB-231, HL-60 and U937 cells were maintained overnight in medium containing $0.5 \%$ FBS at $1 \times 10^{6}$ cells per well in a 6-well plate. After that, CXCL12 $\left(100 \mathrm{ng} \mathrm{mL}^{-1}\right.$ for MCF-7 and MDA-MB-231, $200 \mathrm{ng} \mathrm{mL}^{-1}$ for HL-60, and $50 \mathrm{ng}$ $\mathrm{mL}^{-1}$ for U937) with and without $\mathrm{W} 4$ at a mole ratio of $1: 1$ was added into the medium for $15 \mathrm{~min}$ at $37^{\circ} \mathrm{C}$. Then, adding excess PBS, the cells were washed and lysed in RIPA lysis buffer (Pierce, USA) supplemented with protease inhibitors and a phosphatase 
inhibitor mixture on ice for $1 \mathrm{~h}$. The lysates were clarified by centrifugation at $14000 \mathrm{~g}$ for $10 \mathrm{~min}$. Equal protein $(10 \mu \mathrm{g})$ was loaded and separated on 10\% Bis-Tris gels (Invitrogen, USA), and transferred to PVDF membranes $(0.45 \mu \mathrm{m}$, Millipore, USA). The phosphorylated and total proteins were probed with specific primary antibodies (Akt, phosphorylated-Akt, Erk, phosphorylated-Erk, p38, phosphorylated-p38, and GAPDH; Cell signaling Technology, USA) overnight at $4{ }^{\circ} \mathrm{C}$ and the secondary antibodies conjugated to HRP for $1 \mathrm{~h}$ at room temperature. The immunocomplex on the membrane was visualized using a ChemiDoc ${ }^{\circledR}$ Touch Imaging System (Bio-Rad, USA) with SuperSignal ${ }^{\circledR}$ West Femto Maximum Sensitivity Substrate (Thermo Scientific, USA).

\subsection{Confocal microscopy analysis}

The MCF-7 and MDA-MB-231 cells were seeded at $10 \times 10^{4}$ cells per dish and incubated for $24 \mathrm{~h}$. Then the cells were washed 3 times, followed by supplementation with $1 \mathrm{~mL}$ of culture medium containing $1 \mu \mathrm{M}$ rhodamine B isothiocyanate (RBITC)labeled CXCL12 (Abace Biology, China), $1 \mu \mathrm{M}$ FITC-labeled W4, and $1 \mu \mathrm{M}$ RBITC-labeled CXCL12 with FITC-labeled W4. The cells were incubated for $1 \mathrm{~h}$ at $37^{\circ} \mathrm{C}$. Next the cells were washed and incubated with Hoechst 33342 (Sigma-Aldrich, USA) for $10 \mathrm{~min}$. Images were taken using a laser confocal microscope (LSM760, Zeiss, Germany).

\subsection{Flow cytometry assay}

The MCF-7, MDA-MB-231, HL-60 and U937 cells were washed once with washing buffer (PBS containing $2 \%$ FBS) and then resuspended with culture medium to $5 \times 10^{6}$ cells per mL. $50 \mu \mathrm{L}$ of the cell suspension was added into the tube and centrifuged at $500 \mathrm{~g}$ for $1 \mathrm{~min}$. Then the supernatant was removed carefully. $60 \mu \mathrm{L}$ of RBITC-labeled CXCL12, FITC-labeled W4, and RBITClabeled CXCL12 with FITC-labeled $\mathrm{W} 4$ at $1 \mu \mathrm{M}$ in culture medium were added into the tube. The cells were incubated at room temperature for $1 \mathrm{~h}$ and then washed twice with $1 \mathrm{~mL}$ of washing buffer. Then the supernatant was removed and the cells were resuspended with $500 \mu \mathrm{L}$ of washing buffer. $1 \times 10^{4}$ cells were analyzed by a C6 Accuri flow cytometer (BD Biosciences, USA).

\subsection{Statistical analysis}

All the experiments were carried out in triplicate and Student's $t$-test was performed to assess the statistical significance of the results $(* P<0.05$ and $* * P<0.01)$.

\section{Results and discussion}

\subsection{Binding affinity between $\mathrm{W} 4$ and CXCL12}

To validate the binding parameters (the equilibrium dissociation constant $K_{\mathrm{D}}$ ) between W4 and CXCL12, an SPR assay was employed, which allowed for estimation of the kinetic and binding constants for the interactions between them. A series of concentrations $(50,100$ and $200 \mathrm{nM})$ of CXCL12 were used to investigate the $K_{\mathrm{D}}$ of the binding and the antibody of CXCL12 was also determined as a positive control. We could tell that the
SPR signal intensity increased with the rise in the concentration (Fig. S1†). The sensor grams were recorded for calculation of the quantitative binding kinetic parameters, such as the association rate constant $k_{\mathrm{a}}$ and dissociation rate constant $k_{\mathrm{d}}$, as shown in Table 1 . The $K_{\mathrm{D}}$ values were calculated from the measured $k_{\mathrm{a}}$ and $k_{\mathrm{d}}\left(K_{\mathrm{D}}=k_{\mathrm{d}} / k_{\mathrm{a}}\right)$. As listed, W4 showed comparable binding affinity $\left(5.7 \times 10^{-8} \mathrm{M}\right)$ to that of anti-CXCL12 $\left(3.0 \times 10^{-9} \mathrm{M}\right)$ binding to CXCL12.

Using ELISA and dot blot assay, we next studied the competitive binding between W4 and the antibody of CXCL12 to CXCL12. Early analysis of the binding affinity between W4 and CXCL12 revealed comparable binding capability of W4 with anti-CXCL12, leading to the hypothesis that W4 would compete with anti-CXCL12 to target CXCL12. In the ELISA assay, for the anti-CXCL12 supplemented assay that didn't contain the peptide, the absorbance of HRP-anti-IgG was at a relatively high level. After being treated with $\mathrm{W} 4$, the absorbance was decreased and tested in a concentration-dependent manner, exhibiting that the antibody binding to CXCL12 could be partly replaced by W4 (Fig. 1A). Stronger experimental evidence for the competitive binding between W4 and anti-CXCL12 was shown in the dot blot images. The antibody bound to the protein CXCL12, which led to the development of HRP-anti-IgG positive spots. However, this effect was regulated by treatment with W4 at a mole ratio of $10: 1$ with anti-CXCL12, which showed a light spot (Fig. 1B).

These results clearly indicate that $\mathrm{W} 4$ has comparable binding affinity to that of anti-CXCL12, indicating that W4 could be a possible candidate for targeting CXCL12 for interfering with the binding of CXCL12 to the receptor CXCR4.

\subsection{Transformation of the secondary structure of CXCL12 induced by $\mathrm{W4}$}

Considering that chemokines are rather small proteins, questions concerning the structural change at the binding site for chemokines are raised. ${ }^{32}$ Proteins can fold into several welldefined secondary structures, originating mainly from the strong intramolecular hydrogen bonds, such as $\alpha$-helixes, $\beta$ sheets and random coils. ${ }^{33}$ The conformation of proteins can be changed due to interaction with other molecules, which can influence the formation of the intramolecular hydrogen bonds in the protein. In order to investigate the conformation change of CXCL12 upon W4 addition, the circular dichroism (CD) spectra of CXCL12 with and without W4 interaction were obtained in water. As shown in Fig. 2, the CD spectrum of CXCL12 in solution exhibited a maximum value near $190 \mathrm{~nm}$ and negative values around $200 \mathrm{~nm}$, corresponding to the mixed

Table 1 Kinetic parameters for the binding of anti-CXCL12 and W4 to CXCL12 by SPR

\begin{tabular}{lllll}
\hline \multirow{4}{l}{ Kinetic parameters } \\
\cline { 2 - 5 } & $k_{\mathrm{a}}\left(\mathrm{M}^{-1} \mathrm{~s}^{-1}\right)$ & $k_{\mathrm{d}}\left(\mathrm{s}^{-1}\right)$ & $K_{\mathrm{A}}\left(\mathrm{M}^{-1}\right)$ & $K_{\mathrm{D}}(\mathrm{M})$ \\
\hline Anti-CXCL12 & $2.5 \times 10^{4}$ & $7.6 \times 10^{-5}$ & $3.3 \times 10^{8}$ & $3.0 \times 10^{-9}$ \\
W4 & $1.4 \times 10^{4}$ & $8.0 \times 10^{-4}$ & $1.8 \times 10^{7}$ & $5.7 \times 10^{-8}$
\end{tabular}


$\mathbf{A}$

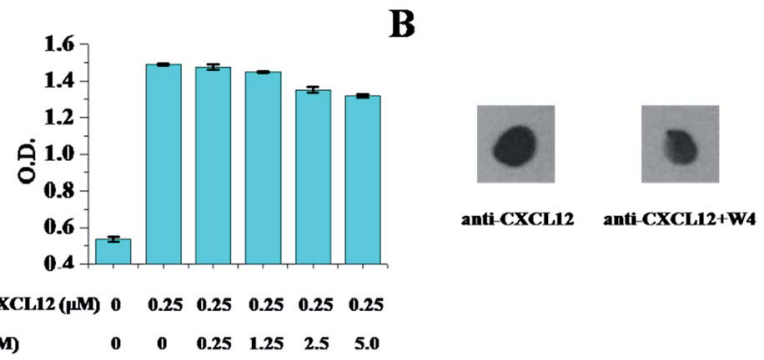

Fig. 1 Competitive binding between anti-CXCL12 and W4. (A) ELISA assay is used to measure the binding levels of anti-CXCL12 to CXCL12 after treatment of different concentrations of W4. The error bars represent the standard deviation $(n=3)$. (B) The dot blot analysis of the binding amount of anti-CXCL12 to CXCL12 after treatment with W4. The mole ratio of anti-CXCL12 to W4 was $1: 10$.

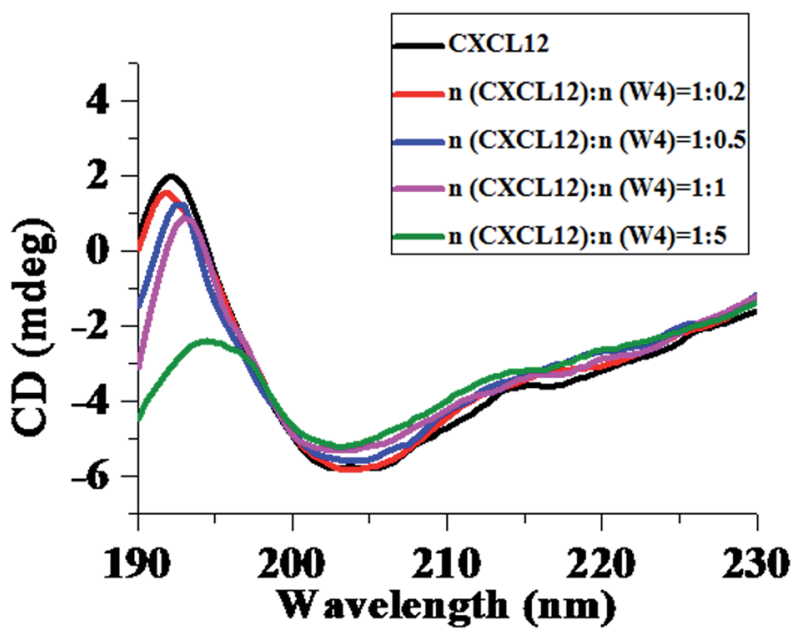

Fig. 2 Transformation of the secondary structures of CXCL12 induced by W4. Every CD spectrum data used was the average of three scans and corrected for the background of the peptide and solvent.

structures of $\alpha$-helix, $\beta$-sheet and random coils, which was consistent with previous reports. ${ }^{34}$ Upon introduction of W4 into the CXCL12 solution, the characteristic peaks near $190 \mathrm{~nm}$ and $200 \mathrm{~nm}$ were weakened, and the positive band shifted to the right little by little, indicating that the $\alpha$-helical structure of CXCL12 gradually transformed into a $\beta$-sheet structure and random coils after interacting with $\mathrm{W} 4$. Analysis within the

Table 2 Secondary structure analysis of CXCL12 after treatment with W4

\begin{tabular}{llllll}
\hline & \multicolumn{5}{l}{ Ratio $(\%)$} \\
\cline { 3 - 6 } & & & & & \\
\cline { 3 - 6 } & & & & & \\
\cline { 3 - 6 } & CXCL12 & $1: 0.2$ & $1: 0.5$ & $1: 1$ & $1: 5$ \\
\hline$\alpha$-Helix & 18.1 & 14.5 & 7.6 & 3.5 & 0 \\
$\beta$-Sheet & 40.5 & 43.2 & 48.3 & 51.9 & 53.2 \\
Random coils & 41.4 & 42.3 & 44.1 & 44.6 & 46.8 \\
Total & 100 & 100 & 100 & 100 & 100
\end{tabular}

software supported the transformation of the secondary structures of CXCL12 by mixing with $\mathrm{W} 4$ at different mole ratios (Table 2), which was in agreement with the CD spectra. The percentages of the $\alpha$-helix, $\beta$-sheet and random coils structures of CXCL12 were $18.1 \%, 40.5 \%$ and $41.4 \%$, respectively. After mixing with the peptide, the secondary structure of CXCL12 was induced into the $\beta$-sheet structure and random coils, manifesting so that the percentage of $\beta$-sheet and random coils increased to $53.2 \%$ and $46.8 \%$, while the $\alpha$-helical structure disappeared when the mole ratio of CXCL12 and W4 was $1: 5$. Therefore, the CD spectra revealed that the addition of W4 could lead to conformation change of CXCL12.

To further reveal the interaction mode between $\mathrm{W} 4$ and CXCL12, the automated docking simulation was performed. The crystal structure of human CXCL12 (PDB ID: 2SDF) was utilized as the target structure, whereas the peptide W4 was used as a docking probe. The molecular docking simulation initiated with AutoDock Vina (Fig. 3) showed the designed recognition peptides were mostly binding to the $\alpha$-helix and random coil domains of CXCL12. According to the illustration, W4 formed intermolecular hydrogen bonds with the CXCL12 proteins, like Arg12, Pro32, Asn33, Leu36, Pro53 and Asn67. More importantly, W4 formed three continuous hydrogen bonds with the Gln59 and Glu63 region of CXCL12, which formed an $\alpha$-helix structure in the C-terminal domain. These interactions appeared to efficiently change the $\alpha$-helical structure of CXCL12 after binding with W4 with high affinity.

\subsection{Inhibition of CXCL12-induced migration of both breast cancer cells and acute myelocytic leukemia cells by W4}

Preclinical studies on different tumor models have revealed that CXCR4 activation mediates tumor cell migration towards the CXCL12 expressing organs, which is a central player in tumor progression. ${ }^{3,35}$ Therefore, in the following chemotaxis experiments, the wound healing assay and transwell assay were utilized to determine whether W4 could weaken the binding of CXCL12 to CXCR4 and then inhibit CXCL12-induced migration of the CXCR4-positive cell lines. The four CXCR4-positive cell lines, MCF-7, MDA-MB-231, HL-60 and U937, were chosen as models and the expression levels of CXCR4 in the four cell lines were determined to be $61.4 \%, 88.1 \%, 97.6 \%$ and $92.5 \%$,

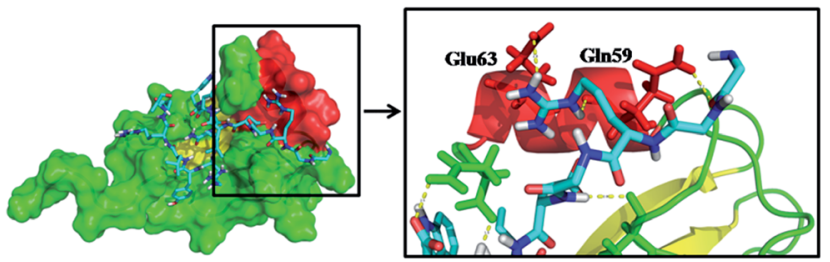

Fig. 3 Molecular modeling simulations of CXCL12 (2SDF) with W4 (aqua sticks). The red, yellow and green parts in the CXCL12 protein structure represent the $\alpha$-helix, $\beta$-sheet and random coil domains, respectively. The zoomed-in part shows the possible hydrogen bonds between Gln59 and Glu63 in the $\alpha$-helix domain of CXCL12 and the Nterminal of W4. The molecular docking studies were initiated with AutoDock Vina. 
respectively [analyzed by flow cytometry (FCM) using the CXCR4 antibody, Fig. S2†].

The wound healing assay is shown in Fig. $4.24 \mathrm{~h}$ after the cell monolayers were wounded, $\sim 30.0 \%$ of MCF-7 cells and $\sim 20.0 \%$ of MDA-MB-231 cells without CXCL12 treatment had filled in the cleared areas. After CXCL12 was supplemented, the adhesive cells were enhanced to migrate into the wounded area (set at $100 \%$ as a control). When treated with $\mathrm{W} 4$, cell migration was significantly inhibited in the two breast cell lines, and the inhibitory effect was associated with the concentration. With the increase in the mole ratio of $\mathrm{W} 4$ to CXCL12, the migration rates gradually reduced, especially when the mole ratio was $1: 1$, where the optimal inhibitory effects reached $30.0 \%$ and $35.0 \%$ for MCF-7 and MDA-MB-231 respectively.

In the transwell assay, CXCL12 was treated with W4 prior to being added to the lower chamber. In the absence of CXCL12, the migration of cells was $\sim 40.0 \%$ for MCF-7 and $\sim 20.0 \%$ for MDA-MB-231, HL-60 and U937 (Fig. 5). When supplied with CXCL12, the cells were enticed to migrate to the lower chamber. By visualizing the cells that migrated to the bottom of the culture inserts, when treated with $\mathrm{W} 4$ at different mole ratios with CXCL12, the migration was markedly inhibited in all cell lines but the migration percentages were relatively high when the concentration of W4 was at a lower level. When the mole ratio reached $1: 1$, the migration percentages were substantially reduced to their minimum of $\sim 20.0 \%$ for MCF-7, $\sim 30.0 \%$ for MDA-MB-231, $\sim 45.0 \%$ for HL-60 and $\sim 40.0 \%$ for U937, completely abolishing the effect of CXCL12.

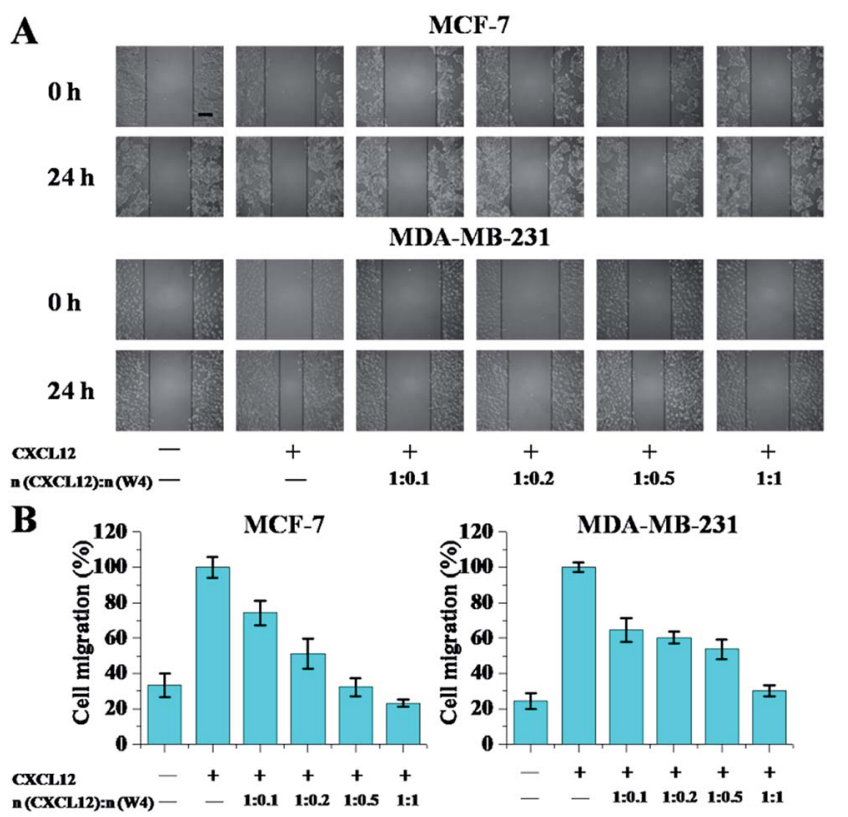

Fig. 4 The wound healing assay showed the inhibitory effect of W4 on cell migration. (A) Representative images showed the migration of two adhesive cancer cells before $(0 \mathrm{~h})$ and after ( $24 \mathrm{~h}) \mathrm{W} 4$ treatment in the presence or absence of CXCL12. The scale bar represents $200 \mu \mathrm{m}$. (B) The areas of the migrated cells were counted at the three selected sites. The CXCL12 supplemented one without W4 was set at $100 \%$ as the control. The error bars represent the standard deviation $(n=3)$.
$\mathbf{A}$
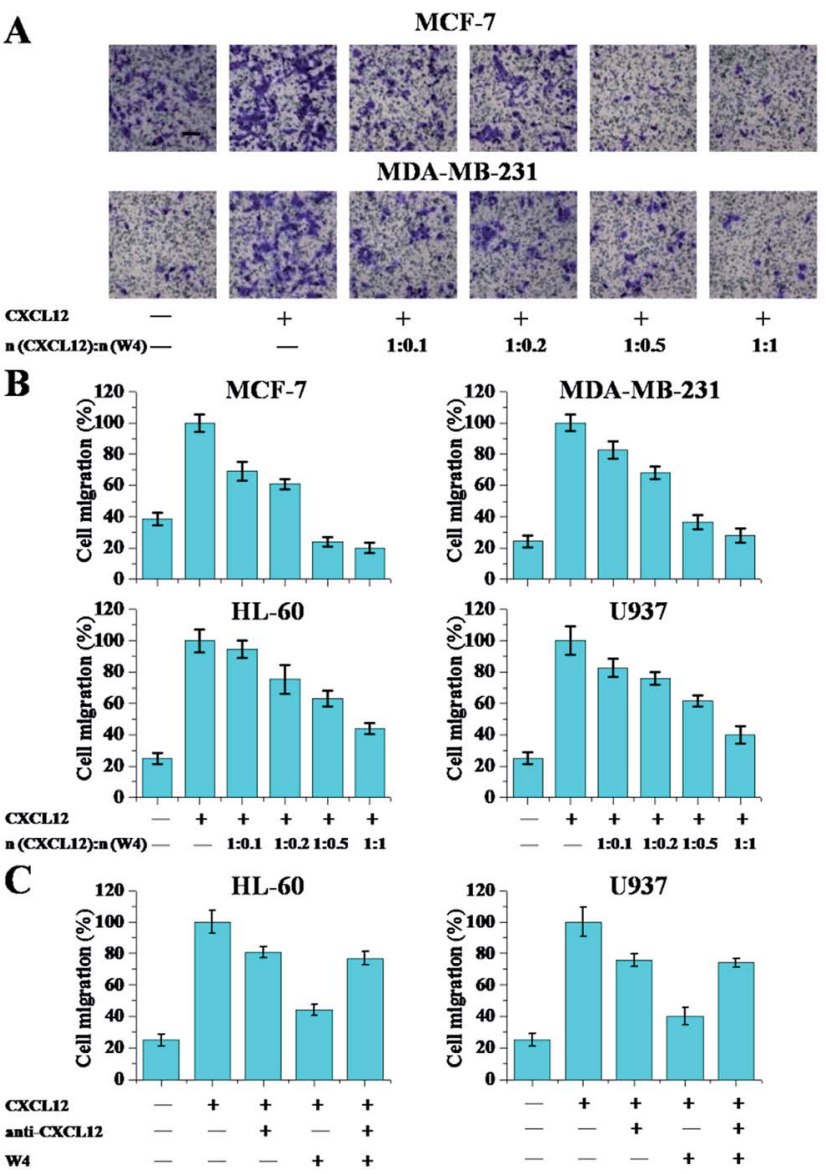

Fig. 5 A transwell assay shows the inhibitory effect of W4 on cell migration. (A) Representative images show the migration of two adhesive cancer cells after W4 treatment for $24 \mathrm{~h}$ in the presence or absence of CXCL12. The scale bar represents $100 \mu \mathrm{m}$. (B) The migrated cells are visualized and counted in five randomly selected fields using a microscope. A CXCL12 supplemented assay without W4 and set to $100 \%$ is used as the control. (C) To confirm the absence of off-target effects of W4 on cell migration, inserts with $\mathrm{HL}-60$ and U937 cells were placed into a well containing $800 \mu \mathrm{L}$ of culture medium in the presence of CXCL12 and $10 \mathrm{mg} \mathrm{mL}^{-1}$ anti-CXCL12, prior to the addition of W4. The molar ratio of CXCL12 to W4 was $1: 1$. The error bars represent the standard deviation $(n=3)$.

To confirm the absence of off-target effects of W4 on cell migration, inserts with HL-60 and U937 cells were placed into a well containing culture medium in the presence of CXCL12 and anti-CXCL12, prior to the addition of W4. It turned out that after binding with anti-CXCL12, CXCL12 could not be inhibited by W4 any more, indicating that W4 targeted CXCL12 specifically and thus was functioning (Fig. 5C). Overall, these changes indicate that W4 could more effectively inhibit CXCL12-induced cell migration of both the breast cancer cell lines and acute myelocytic leukemia cell lines that are overexpressing CXCR4.

We have provided biological data to show that a peptide is able to bind to the chemokine CXCL12, and thus alter the functional consequences of the interaction between CXCL12 and its receptor CXCR4, as demonstrated here by the inhibition of in vitro chemotaxis. Considering that chemokines are rather small proteins, our observations raise questions concerning the 
molecular mechanism of the neutralizing molecule W4. It has been reported that CXCL12 binds to CXCR4 in a two-step process. First, the extracellular flexible $\mathrm{N}$-terminal domain of the receptor recognizes and binds to the surface of CXCL12, and then CXCL12 "docks" its own flexible N-terminal domain into the receptor resulting in activation and downstream signaling. ${ }^{36}$ The first step, however, represents a viable alternative target and a prototypic example of protein-protein interactions, mediated by a binding surface area covering a large portion of the chemokine. From the molecular docking results, we could see that W4 wraps nearly halfway around the chemokine, creating an interface that prevents the binding between CXCL12 and the CXCR4 N-terminus (Fig. 3). Noteworthy, the reported binding affinity of CXCL12 for CXCR4 $\left(K_{\mathrm{D}} \sim 2 \text { to } 4 \times 10^{-9} \mathrm{M}\right)^{37,38}$ is one order of magnitude higher than that of W4 for CXCL12 $\left(K_{\mathrm{D}}=5.7\right.$ $\times 10^{-8} \mathrm{M}$, Table 1$)$. Compared with the significant inhibitory effects of W4 on cell migration (Fig. 4 and 5), we speculated that competitive inhibition might not be the sole reason for blocking of the CXCL12/CXCR4 axis.

On the other hand, it has been described that minor modifications to the conformation of a protein are nevertheless sufficient to affect the protein's ability to bind to, or properly interact with, its substrates, which is a common form of allosteric regulation. ${ }^{39,40}$ Volkman and his colleagues found the allosteric behavior of the chemokine CXCL12 with a CXCR4 peptide increased the CXCL12 dimerization affinity by allosteric coupling at its binding site. ${ }^{32}$ In our work, the CD spectrum of CXCL12 in solution shows that its conformation was changed upon interaction with $\mathrm{W} 4$ as the $\alpha$-helical structure disappeared and transformed into $\beta$-sheet and random coil structures (Fig. 2 and 3 ). We could propose a hypothesis that the coordinated movement of the segments of CXCL12 might transmit the allosteric signal to the active site on the $\mathrm{N}$-terminal tail of CXCL12, which is deformed, and dramatically reduce the interaction of CXCL12 with its receptor CXCR4.

However, with the increase of the mole ratio of W4 to CXCL12, the inhibitory effects detected on the four cell lines all slightly decreased (Fig. S3 and S4†), perhaps because W4 had a mild tendency of aggregation over $24 \mathrm{~h}$, which led to a lower effective drug concentration being obtained at the target protein (Fig. $\mathrm{S} 5 \dagger$ ).

\subsection{Down-regulation of CXCL12-induced expression of genes and proteins by $\mathrm{W} 4$}

CXCR4/CXCL12 interaction has been demonstrated to increase the expression of the Vimentin, N-cadherin, MMP-2 and MMP-9 genes, which accounts for the invasion and metastasis of tumor cells. ${ }^{\mathbf{8 , 4 1}}$ To clarify whether W4 inhibits cell migration through affecting the intracellular signaling of CXCL12/CXCR4, we performed realtime fluorescence quantitative PCR for activation of the Vimentin, N-cadherin, MMP-2 and MMP-9 genes in the four cell lines. The cells were treated with CXCL12 alone, and CXCL12 with W4 at a mole ratio of $1: 1$. As shown in Fig. 6, CXCL12 treatment enhanced the expression levels of the Vimentin, N-cadherin, MMP-2 and MMP-9 genes in reference to that of the control, while treatment with W4 significantly
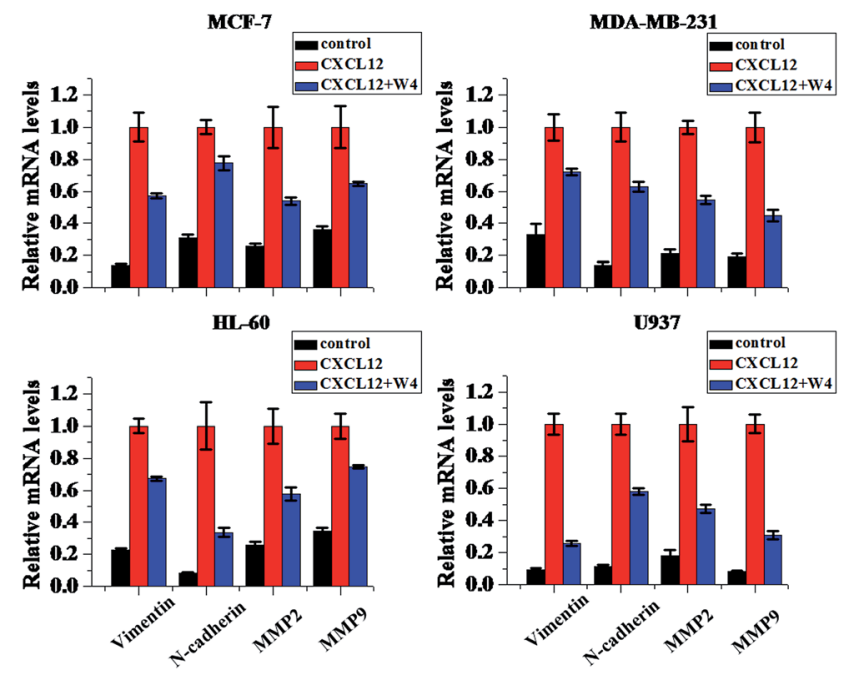

Fig. 6 Effects of W4 on the CXCL12-induced activation of genes including Vimentin, N-cadherin, MMP2 and MMP9 determined by realtime fluorescence quantitative PCR. GAPDH mRNA was used to normalize the variability in template loading. The mole ratio of CXCL12 to W4 was $1: 1$. The error bars represent the standard deviation $(n=3)$.

diminished the CXCL12-induced gene expression. These results clearly indicated that W4 could interact with CXCL12 and then inhibit cancer cells from responding to CXCL12 stimulation by suppressing the expression of the Vimentin, N-cadherin, MMP2 and MMP-9 genes.

For upstream proteins, the stimulation of CXCL12 on CXCR4 results in the activation of Akt, Erk and p38. ${ }^{42-44}$ We next conducted western blot analysis for activation of Akt (phospho-Akt), Erk (phospho-Erk) and p38 (phospho-p38) in the four kinds of CXCR4-positive cell lines to further clarify whether W4 inhibits cell migration through affecting the intracellular signaling of CXCL12/CXCR4. The results displayed in Fig. 7 show that CXCL12 treatment enhanced the phosphorylation levels of Akt, Erk and p38 (lane b) in reference to that of the control, while W4 dramatically inhibited the robust phosphorylation of Akt, Erk and p38 in the cells stimulated by CXCL12 (lane c). These results clearly indicate that $\mathrm{W} 4$ inhibits CXCR4-positive cells from responding to CXCL12 stimulation by suppressing the expression of p-Akt, p-Erk and p-p38.

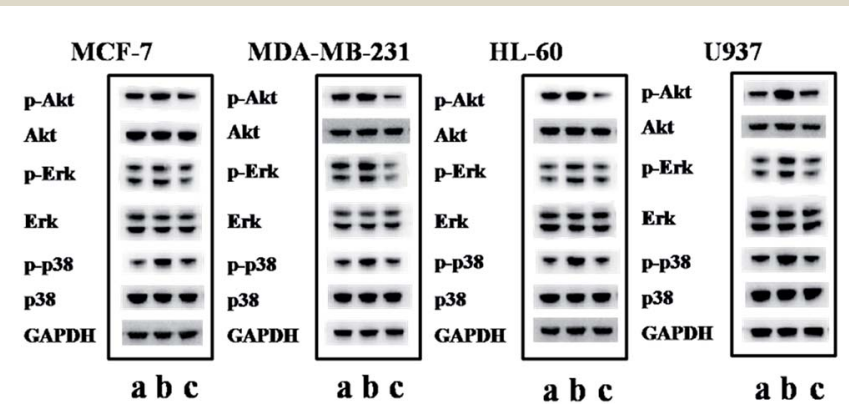

Fig. 7 Effects of W4 on CXCL12-induced Akt, Erk and p38 activation of cancer cells by western blot analysis. (a) Control, (b) CXCL12 treatment only, and (c) treated with CXCL12 and W4 at a mole ratio of $1: 1$. 


\subsection{W4 binds to CXCL12 but not to the receptor CXCR4}

The evidence supporting W4 binding to CXCL12 was provided by analysis using confocal microscopy. The results of the two adhesive breast cancer cell lines are displayed representatively in Fig. 8A. When the cells were incubated with RBITC-labeled CXCL12 alone, we found brighter red fluorescence dispersed on the whole cell membrane uniformly. If W4 was used to interact with CXCL12, the signals of red fluorescence were observed to decrease on the cell membrane, which indicated that the amount of CXCL12 bound to the cell membrane reduced after interacting with $\mathrm{W} 4$. However, when the cells were incubated in medium containing FITC-W4, the green fluorescence on the cell membrane was faint in both cells (Fig. S6†). After treatment with CXCL12, the intensity on the cell surface was attenuated and even negligible for the green fluorescence, which proved that W4 didn't bind to the cell surface. In order to illustrate the amounts of CXCL12 bound to the cell surface, we performed FCM assay. The results showed that lower mean fluorescent intensity (MFI) could be observed after interaction with W4 (Fig. 8B). These data revealed that W4 interacted with CXCL12 and neutralized its binding capacity to its receptor CXCR4, but did not act directly on CXCR4.

The CXCR4/CXCL12 axis is a target for therapeutics that block their interaction to inhibit downstream intracellular enzyme activities, as well as to interfere with the stromal cellmediated tumor cell drug-resistance. In view of the great importance of the CXCL12/CXCR4 axis in the spread of different types of tumors, multiple antagonists targeting the ligand or receptor have been developed. Considering that W4 exhibits potent anti-metastasis activity upon binding to CXCL12 but not to CXCR4, its mechanism of action markedly differs from that of other pharmacological agents acting upon binding to the receptor CXCR4, such as the small molecule AMD3100 (ref. 23 and 45) and peptide T140. ${ }^{19,20}$ The analysis of the functional

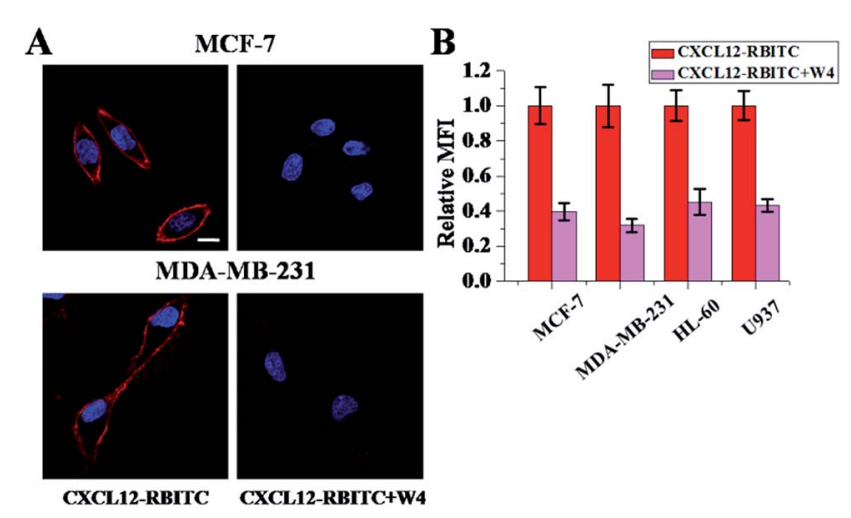

Fig. 8 The amounts of CXCL12 bound to the cells after treatment with W4. (A) Confocal microscopy images of CXCL12 (left line) and CXCL12 with W4 (right line) bound to two adhesive cancer cells were obtained using RBITC labeled CXCL12, and the nucleus was revealed with Hoechst 33342 (blue fluorescence). The scale bar represents $10 \mu \mathrm{m}$. (B) The amounts of CXCL12 bound to the cell surface after treatment with W4 were measured by FCM analysis. The CXCL12 treated group was set as 1 . The error bars represent the standard deviation $(n=3)$. The mole ratio of CXCL12 to W4 was $1: 1$. properties of these antagonists on constitutively active mutants of CXCR4 reveals that, at high doses, AMD3100 is a weak partial agonist and T140 is an inverse agonist of the receptor functions. ${ }^{46}$ As a consequence, both AMD3100 and T140 are cautiously considered to be anti-metastatic agents in many cancer types involving CXCR4. ${ }^{47}$ In contrast to the CXCR4 antagonists, the anti-ligand molecules do not alter the basal function of the receptor CXCR4.

It is notable that to date, the peptide antagonists for CXCL12 itself have been rarely published. Therefore, it is necessary and of significance to develop peptide antagonists targeting CXCL12 for use in anti-metastasis, so that more therapeutic options can be provided to patients. Contrary to those small molecules, ${ }^{24,26}$ W4 is designed according to the sequence features of human CXCL12 and chemically synthesized, rather than derived from any natural compounds, which makes it more easily, flexibly and economically produced. Another attractive feature of this peptide targeting the chemokine is that it has no cytotoxicity to cells up to a high concentration of $30 \mu \mathrm{M}$ (Fig. S7 $\dagger$ ). It is thus interesting to consider anti-ligand peptides as pharmacological agents with mechanisms of action that differ from traditional competitive antagonists binding to the receptor.

\section{Conclusion}

We demonstrate a peptide W4 that interacts with CXCL12 with high binding affinity $\left(5.7 \times 10^{-8} \mathrm{M}\right)$. As a result, the conformation change of CXCL12 can be identified, thereby the CXCL12/CXCR4 axis can be blocked leading to impacts on the subsequent biological functions, manifesting such that W4 inhibits the CXCL12-induced cell migration by down-regulating the activation of the Akt, Erk and p38 signaling pathway. We speculate allosteric coupling at the binding site of CXCL12 to W4 and the conformational change caused might transmit the signal to the active site of CXCL12, which dramatically reduces the interaction of CXCL12 with its receptor CXCR4. These results may provide an alternative means of drug design to target ligand-receptor interactions using anti-ligand peptides as therapeutic agents.

\section{Acknowledgements}

This work was supported by the National Natural Science Foundation of China (Grant No. 21273051, 21673055). The Beijing Natural Science Foundation (Grant No. 2162044) is also gratefully acknowledged. Financial support from CAS Key Laboratory of Standardization and Measurement for Nanotechnology is also gratefully acknowledged.

\section{References}

1 F. Y. Jin, U. Brockmeier, F. Otterbach and E. Metzen, Mol. Cancer Res., 2012, 10, 1021-1031.

2 C. L. Chaffer and R. A. Weinberg, Science, 2011, 331, 15591564.

3 B. A. Teicher and S. P. Fricker, Clin. Cancer Res., 2010, 16, 2927-2931. 
4 J. A. Burger and T. J. Kipps, Blood, 2006, 107, 1761-1767.

5 A. Muller, B. Homey, H. Soto, N. F. Ge, D. Catron, M. E. Buchanan, T. McClanahan, E. Murphy, W. Yuan, S. N. Wagner, J. L. Barrera, A. Mohar, E. Verastegui and A. Zlotnik, Nature, 2001, 410, 50-56.

6 M. C. P. Smith, K. E. Luker, J. R. Garbow, J. L. Prior, E. Jackson, D. Piwnica-Worms and G. D. Luker, Cancer Res., 2004, 64, 8604-8612.

7 R. S. Taichman, C. Cooper, E. T. Keller, K. J. Pienta, N. S. Taichman and L. K. McCauley, Cancer Res., 2002, 62, 1832-1837.

8 S. Singh, U. P. Singh, W. E. Grizzle and J. W. Lillard, Lab. Invest., 2004, 84, 1666-1676.

9 S. Brand, J. Dambacher, F. Beigel, T. Olszak, J. Diebold, J. M. Otte, B. Goke and S. T. Eichhorst, Exp. Cell Res., 2005, 310, 117-130.

10 J. Kim, H. Takeuchi, S. T. Lam, R. R. Turner, H.-J. Wang, C. Kuo, L. Foshag, A. J. Bilchik and D. S. Hoon, J. Clin. Oncol., 2005, 23, 2744-2753.

11 Y. Alsayed, H. Ngo, J. Runnels, X. Leleu, U. K. Singha, C. M. Pitsillides, J. A. Spencer, T. Kimlinger, J. M. Ghobrial, X. Y. Jia, G. W. Lu, M. Timm, A. Kumar, D. Cote, I. Veilleux, K. E. Hedin, G. D. Roodman, T. E. WitZig, A. L. Kung, T. Hideshima, K. C. Anderson, C. P. Lin and I. M. Ghobrial, Blood, 2007, 109, 2708-2717.

12 Z. H. Zeng, Y. X. Shi, I. J. Samudio, R. Y. Wang, X. Y. Ling, O. Frolova, M. Levis, J. B. Rubin, R. R. Negrin, E. H. Estey, S. Konoplev, M. Andreeff and M. Konopleva, Blood, 2009, 113, 6215-6224.

13 S. Tavor, I. Petit, S. Porozov, A. Avigdor, A. Dar, L. LeiderTrejo, N. Shemtov, V. Deutsch, E. Naparstek, A. Nagler and T. Lapidot, Cancer Res., 2004, 64, 2817-2824.

14 J. A. Burger, M. Burger and T. J. Kipps, Blood, 1999, 94, 36583667.

15 D. A. Sipkins, X. B. Wei, J. W. Wu, J. M. Runnels, D. Cote, T. K. Means, A. D. Luster, D. T. Scadden and C. P. Lin, Nature, 2005, 435, 969-973.

16 J. A. Burger and A. Burkle, Br. J. Haematol., 2007, 137, 288296.

17 A. Zepeda-Moreno, R. Saffrich, T. Walenda, V. T. Hoang, P. Wuchter, S. Sanchez-Enriquez, A. Corona-Rivera, W. Wagner and A. D. Ho, Exp. Hematol., 2012, 40, 666-674.

18 B. Debnath, S. L. Xu, F. Grande, A. Garofalo and N. Neamati, Theranostics, 2013, 3, 47-75.

19 M. Burger, T. Hartmann, M. Krome, J. Rawluk, H. Tamamura, N. Fujii, T. J. Kipps and J. A. Burger, Blood, 2005, 106, 1824-1830.

20 Z. X. Liang, T. Wu, H. Lou, X. W. Yu, R. S. Taichman, S. K. Lau, S. M. Nie, J. Umbreit and H. Shim, Cancer Res., 2004, 64, 4302-4308.

21 A. Ottaiano, A. di Palma, M. Napolitano, C. Pisano, S. Pignata, F. Tatangelo, G. Botti, A. Acquaviva, G. Castello, P. Ascierto, R. Iaffaioli and S. Scala, Cancer Immunol. Immunother., 2005, 54, 781-791.

22 M. R. Kuhne, T. Mulvey, B. Belanger, S. Chen, C. Pan, C. L. Chong, F. Cao, W. Niekro, T. Kempe, K. A. Henning,
L. J. Cohen, A. J. Korman and P. M. Cardarelli, Clin. Cancer Res., 2013, 19, 357-366.

23 J. A. Burger and A. Peled, Leukemia, 2009, 23, 43-52.

24 W. W. Wen, S. Xie, X. L. Xin, M. Y. Geng, J. Ding and Y. Chen, Acta Pharmacol. Sin., 2013, 34, 1554-1559.

25 C. Laguri, F. Arenzana-Seisdedos and H. Lortat-Jacob, Carbohydr. Res., 2008, 343, 2018-2023.

26 M. Hachet-Haas, K. Balabanian, F. Rohmer, F. Pons, C. Franchet, S. Lecat, K. Y. C. Chow, R. Dagher, P. Gizzi, B. Didier, B. Lagane, E. Kellenberger, D. Bonnet, F. Baleux, J. Haiech, M. Parmentier, N. Frossard, F. ArenzanaSeisdedos, M. Hibert and J. L. Galzi, J. Biol. Chem., 2008, 283, 23189-23199.

27 I. Kalatskaya, Y. A. Berchiche, S. Gravel, B. J. Limberg, J. S. Rosenbaum and N. Heveker, Mol. Pharmacol., 2009, 75, 1240-1247.

28 R. A. Laskowski, F. Gerick and J. M. Thornton, FEBS Lett., 2009, 583, 1692-1698.

29 X. Mao, Y. Guo, C. Wang, M. Zhang, X. Ma, L. Liu, L. Niu, Q. Zeng, Y. Yang and C. Wang, ACS Chem. Neurosci., 2011, 2, 281-287.

30 X.-B. Mao, C.-X. Wang, X.-K. Wu, X.-J. Ma, L. Liu, L. Zhang, L. Niu, Y.-Y. Guo, D.-H. Li, Y.-L. Yang and C. Wang, Proc. Natl. Acad. Sci. U. S. A., 2011, 108, 19605-19610.

31 C. Wang, X. Mao, A. Yang, L. Niu, S. Wang, D. Li, Y. Guo, Y. Wang, Y. Yang and C. Wang, Chem. Commun., 2011, 47, 10638-10640.

32 J. J. Ziarek, A. E. Getschman, S. J. Butler, D. Taleski, B. Stephens, I. Kufareva, T. M. Handel, R. J. Payne and B. F. Volkman, ACS Chem. Biol., 2013, 8, 1955.

33 O. Koch, M. Bocola and G. Klebe, Proteins: Struct., Funct., Bioinf., 2005, 61, 310-317.

34 J. W. Murphy, Y. Cho, A. Sachpatzidis, C. Fan, M. E. Hodsdon and E. Lolis, J. Biol. Chem., 2007, 282, 10018-10027.

35 X. Q. Sun, G. C. Cheng, M. G. Hao, J. H. Zheng, X. M. Zhou, J. A. Zhang, R. S. Taichman, K. J. Pienta and J. H. Wang, Cancer Metastasis Rev., 2010, 29, 709-722.

36 E. W. Smith, A. M. Nevins, Z. Qiao, Y. Liu, A. E. Getschman, S. L. Vankayala, M. T. Kemp, F. C. Peterson, R. Li, B. F. Volkman and Y. Chen, J. Med. Chem., 2016, 59, 43424351.

37 M. P. Crump, J. H. Gong, P. Loetscher, K. Rajarathnam, A. Amara, F. Arenzana-Seisdedos, J. L. Virelizier, M. Baggiolini, B. D. Sykes and I. Clark-Lewis, EMBO J., 1997, 16, 6996-7007.

38 K. Balabanian, B. Lagane, S. Infantino, K. Y. Chow, J. Harriague, B. Moepps, F. Arenzana-Seisdedos, M. Thelen and F. Bachelerie, J. Biol. Chem., 2005, 280, 35760-35766.

39 I. A. Shumilin, C. Zhao, R. Bauerle and R. H. Kretsinger, J. Mol. Biol., 2002, 320, 1147-1156.

40 E. Latz, A. Verma, A. Visintin, M. Gong, C. M. Sirois, D. C. Klein, B. G. Monks, C. J. McKnight, M. S. Lamphier and W. P. Duprex, Nat. Immunol., 2007, 8, 772-779.

41 Y. Zhu, P. Yang, Q. Wang, J. Hu, J. Xue, G. Li, G. Zhang, X. Li, W. Li, C. Zhou, M. Zhao and D. Wang, Anat. Rec., 2013, 296, 1850-1856. 
42 B. Lv, X. Yang, S. Lv, L. Wang, K. Fan, R. Shi, F. Wang, H. Song, X. Ma, X. Tan, K. Xu, J. Xie, G. Wang, M. Feng and L. Zhang, Mol. Neurobiol., 2015, 52, 1263-1268.

43 P. Kukreja, A. B. Abdel-Mageed, D. Mondal, K. Liu and K. C. Agrawal, Cancer Res., 2005, 65, 9891-9898.

44 L. J. Bendall, R. Baraz, J. Juarez, W. Shen and K. F. Bradstock, Cancer Res., 2005, 65, 3290-3298.
45 E. De Clercq, Mol. Pharmacol., 2000, 57, 833-839.

46 W.-b. Zhang, J.-M. Navenot, B. Haribabu, H. Tamamura, K. Hiramatu, A. Omagari, G. Pei, J. P. Manfredi, N. Fujii and J. R. Broach, J. Biol. Chem., 2002, 277, 24515-24521.

47 F. Balkwill, Semin. Cancer Biol., 2004, 14, 171-179. 